\title{
EXISTENCE AND UNIQUENESS OF FIXED POINT THEOREMS IN PARTIALLY ORDERED METRIC SPACES
}

\author{
A.MURALIRAJ R.JAHIR HUSSAIN \\ P.G. and Research Department of Mathematics, Urumu Dhanalakshmi \\ College, Kattur, Tiruchirappalli-620 019, TamilNadu, India. \\ P.G. and Research Department of Mathematics, Jamal Mohamed \\ College(Autonomous), Tiruchirappalli-620 020, Tamil Nadu, India.
}

\begin{abstract}
The purpose of this paper is to present a fixed point theorem using a contractive com of rational type and involves combining the ideas of an iterative technique in the co raction ma ing principle with those in the monotone technique in the context of partially ordered m spaces

\section{Introduction}

In $[3,6,16]$, it is proved that some fixed theorems for a mixed space endowed with a partial order and the authors apply their re uniqueness of solutions for some boundary value problems.
\end{abstract}

In the context of partially ordered metric spaces, the usy contractive con ation is weakened but at the expense that the operator is monotone. The mai idea involves combining the ideas of an iterative technique in the contraction mapping prin le with th se in the monotone iterative technique .

\section{Main Result}

Definition 2.1: Let $(X, \leq)$ be $a$ lly or red set and $T: X \rightarrow X$. We say that $T$ is a nondecreasing mapping if for $\mathrm{x}, \mathrm{Y}, \mathrm{x}<\mathrm{v} \Rightarrow \mathrm{Tx}=\mathrm{T} \mathrm{y}$.

Theorem 2.2: Let ( $\mathrm{X},<$ partially dered set and suppose that there exists a metric $\mathrm{d}$ in $\mathrm{X}$ such that $\mathrm{X}, \mathrm{d}$ is a yplete ric space. Let $\mathrm{T}: \mathrm{X} \rightarrow \mathrm{X}$ be a continuous and nondecreasing mapping such th?

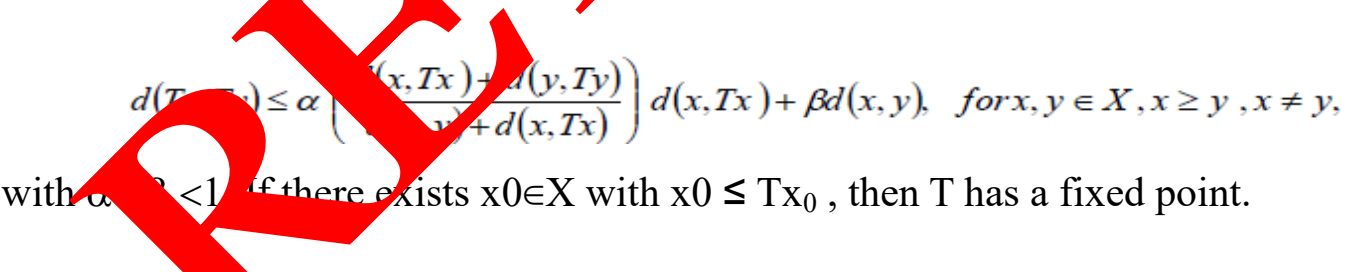

Proof: If $T x_{t} x_{0}$, then the proof is finished. Suppose that $x_{0}<\mathrm{Tx}_{0}$. Since $T$ is a nondecreasing mapping, we sotain by induction that

$$
\mathrm{x}_{0}<\mathrm{Tx}_{0} \leq \mathrm{T}^{2} \mathrm{x}_{0} \leq \cdots \leq \mathrm{T}^{\mathrm{n}} \mathrm{x}_{0} \leq \mathrm{T}^{\mathrm{n}+1} \mathrm{x}_{0} \leq \cdots
$$

Put $x_{n}+1=T x_{n}$. If there exists $n \geq 1$ such that $x_{n}+1=x_{n}$, then from $x n+1=T x_{n}=x_{n}, x_{n}$ is a fixed point and the proof is finished.

Suppose that $\mathrm{x}_{\mathrm{n}}+1 \neq \mathrm{x}_{\mathrm{n}}$ for $\mathrm{n} \geq 1$ 
Then, from (1) and as the elements $\mathrm{x}_{\mathrm{n}}$ and $\mathrm{x}_{\mathrm{n}-1}$ are comparable, we get, for $\mathrm{n} \geq 1$,

$$
\begin{aligned}
d\left(x_{n+1}, x_{n}\right) & =d\left(T x_{n}, T x_{n-1}\right) \\
& \leq \alpha\left(\frac{d\left(x_{n}, T x_{n}\right)+d\left(x_{n-1}, T x_{n-1}\right)}{d\left(x_{n}, x_{n-1}\right)+d\left(x_{n}, T x_{n}\right)}\right) d\left(x_{n}, T x_{n}\right)+\beta d\left(x_{n}, x_{n-1}\right) \\
= & \alpha\left(\frac{d\left(x_{n}, x_{n+1}\right)+d\left(x_{n-1}, x_{n}\right)}{d\left(x_{n}, x_{n-1}\right)+d\left(x_{n}, x_{n+1}\right)}\right) d\left(x_{n}, x_{n+1}\right)+\beta d\left(x_{n}, x_{n-1}\right) \\
& =\alpha d\left(x_{n}, x_{n+1}\right)+\beta d\left(x_{n}, x_{n-1}\right)
\end{aligned}
$$

The last inequality gives us

$$
d\left(x_{n+1}, x_{n}\right) \leq\left(\frac{\beta}{1-\alpha}\right) d\left(x_{n}, x_{n-1}\right)
$$

Again, using induction

$$
k=\frac{\beta}{1-\alpha}<1 .
$$$$
d\left(x_{n+1}, x_{n}\right) \leq\left(\frac{\beta}{1-\alpha}\right)^{n} d\left(x_{1}, x_{0}\right)
$$

Moreover, by the triangular inequality we have or $\mathrm{m} \geq \mathrm{n}$,

$$
d\left(x_{m}, x_{n}\right) \leq d\left(x_{m}, x_{p}\right.
$$

and this proveo $\mathrm{d}\left(\mathrm{m}, \mathrm{x}_{\mathrm{n}} \rightarrow 0\right.$ as $\mathrm{m}, \mathrm{n} \rightarrow \infty$.

So, $\left\{\mathrm{x}_{\mathrm{n}}\right\}$ is a Cauch, quenc and since $\mathrm{X}$ is a complete metric space, there exists



Further, - onmon of $T$ implies

$$
z=T\left(\lim _{n \rightarrow \infty} x_{n}\right)=\lim _{n \rightarrow \infty} T x_{n}=\lim _{n \rightarrow \infty} x_{n+1}=z
$$

And this proves that $\mathrm{z}$ is a fixed point .

Theorem 2.3: Let $(\mathrm{X}, \leq)$ be a partially ordered set and suppose that there exists a metric $\mathrm{d}$ in $\mathrm{X}$ such that $(\mathrm{X}, \mathrm{d})$ is a complete metric space. Assume that the following hypothesis in $\mathrm{X}$ satisfies, if $\left\{\mathrm{X}_{\mathrm{n}}\right\}$ is a nondecreasing sequence in $\mathrm{X}$ such that $\mathrm{x}_{\mathrm{n}} \rightarrow \mathrm{X}$, then $\mathrm{x}=\sup \left\{\mathrm{x}_{\mathrm{n}}\right\}$. Let $\mathrm{T}: \mathrm{X} \rightarrow \mathrm{X}$ be a nondecreasing mapping such that 


$$
d(T x, T y) \leq \alpha\left(\frac{d(x, T x)+d(y, T y)}{d(x, y)+d(x, T x)}\right) d(x, T x)+\beta d(x, y), \text { for } x, y \in X, x \geq y, x \neq y,
$$

with $\alpha+\beta<1$. If there exists $\mathrm{x}_{0} \in \mathrm{X}$ with $\mathrm{x}_{0} \leq \mathrm{T} \mathrm{x} 0$, then $\mathrm{T}$ has a fixed point.

Proof: Following the proof of Theorem 2.2., We only have to check that $\mathrm{Tz}=\mathrm{z}$.

As $\{\mathrm{xn}\}$ nondecreasing sequence in $\mathrm{X}$ and $\mathrm{xn} \rightarrow \mathrm{z}$, then $\mathrm{z}=\sup \{\mathrm{xn}\}$.

Particularly, $\mathrm{x}_{\mathrm{n}} \leq \mathrm{z}$ for all $\mathrm{n} \in \mathrm{N}$.

Since $\mathrm{T}$ is a nondecreasing mapping, then $\mathrm{Tx}_{\mathrm{n}} \leq \mathrm{Tz}$, for all $\mathrm{n} \in \mathrm{N}$, or equivalently,

$\mathrm{x}_{\mathrm{n}+1} \leq \mathrm{Tz}$ for all $\mathrm{n} \in \mathrm{N}$.

Moreover, as $\mathrm{x} 0<\mathrm{x} 1 \leq \mathrm{Tz}$ and $\mathrm{z}=\sup \left\{\mathrm{x}_{\mathrm{n}}\right\}$, we get $\mathrm{z} \leq \mathrm{Tz}$.

Suppose that $\mathrm{z}<\mathrm{Tz}$. Using a similar argument that in the proof of theorem 20 , fo $0 \leq \mathrm{Tx} 0$ we obtain that $\left\{\mathrm{T}^{\mathrm{n}} \mathrm{z}\right\}$ is a nondecreasing sequence and

$\lim _{n \rightarrow \infty} T^{n} z=y$ for certain $\mathrm{y} \in \mathrm{X}$.

Aga in us ing $\mathrm{h}$ ypothe $\mathrm{s}$ i s , we have that $\mathrm{y}=\sup \{\mathrm{T} \mathrm{n} \mathrm{z}\}$

Moreover from $x_{0} \leq \mathrm{z}$, we get $\mathrm{x}_{\mathrm{n}}=\mathrm{T}^{\mathrm{n}} \mathrm{x} 0 \leq \mathrm{T}^{\mathrm{n}} \mathrm{z}$ for $\mathrm{n} \geq 1$ and $\mathrm{xn} \leq \mathrm{T}^{\mathrm{n}} \mathrm{z}$ ty 1 because $\mathrm{x}_{\mathrm{n}} \leq \mathrm{z}$ $<\mathrm{Tz} \leq \mathrm{T}^{\mathrm{n}} \mathrm{z}$ for $\mathrm{n} \geq 1$.

As $\mathrm{x}_{\mathrm{n}}$ and $\mathrm{T}^{\mathrm{n}} \mathrm{z}$ are comparable and distinct for $\mathrm{n} \geq 1$, app the $\mathrm{c}$ ntractive condition we get,

$$
\begin{aligned}
d\left(x_{n+1}, T^{n} z\right) & =d\left(T x_{n}, T\left(T^{n} z\right)\right) \\
& \leq \alpha\left(\frac{d\left(x_{n}, T x_{n}\right)+d\left(T^{n} z, T^{n}\right)}{d\left(x_{n} z^{n}\right)+\left(x_{n}, T x_{n}\right)} d\left(x_{n}, T x_{n}\right)+\beta d\left(x_{n}, T^{n} z\right)\right. \\
& =\alpha\left(d\left(x_{n}, T^{n} z, \frac{1}{\left(x_{n}, x_{n+1}\right)}\right) d\left(x_{n}, x_{n+1}\right)+\beta d\left(x_{n}, T^{n} z,\right)\right.
\end{aligned}
$$

As $\beta<1, d(z, y)=0$, thus $z=y$

Particularly $\mathrm{z}=\mathrm{y} \quad \mathrm{p}\left\{\mathrm{T}^{\mathrm{H}} \mathrm{z}\right\}$ and consequently, $\mathrm{Tz} \leq \mathrm{z}$ and this is a contradiction.

Hence we clude th $=\mathrm{Tz}$.

Theorem Let $(X, \leq)$ be a partially ordered set and suppose that there exists a metric $d$ in $X$ such that $(X, Y$ is a complete metric space. Assume that for $x, y \in X$, there exists $z \in X$ which is comparable to $\mathrm{x}$ and $\mathrm{y}$. Let $\mathrm{T}: \mathrm{X} \rightarrow \mathrm{X}$ be a nondecreasing mapping such that

$$
d(T x, T y) \leq \alpha\left(\frac{d(x, T x)+d(y, T y)}{d(x, y)+d(x, T x)}\right) d(x, T x)+\beta d(x, y), \text { for } x, y \in X, x \geq y, x \neq y,
$$

with $\alpha+\beta<1$.If there exists $\mathrm{x} 0 \in \mathrm{X}$ with $\mathrm{x} 0 \leq \mathrm{Tx} 0$, then $\mathrm{T}$ has a fixed point.

Proof : Suppose that there exists $z, y \in X$ which are fixed point . We distinguish two cases. 
Case (1): If $\mathrm{y}$ and $\mathrm{z}$ are comparable and $\mathrm{y} \neq \mathrm{z}$, then using the contractive condition we have,

$$
\begin{aligned}
d(y, z)=d(T y, T z) & \leq \alpha\left(\frac{d(y, T y)+d(z, T z)}{d(y, z)+d(y, T y)}\right) d(y, T y)+\beta d(y, z) \\
= & \alpha\left(\frac{d(y, y)+d(z, z)}{d(y, z)+d(y, y)}\right) d(y, y)+\beta d(y, z) \\
= & \beta d(y, z) .
\end{aligned}
$$

As $\beta<1$ is the last inequality, it is a contradiction. Thus $y=z$.

Case (2) : If $y$ is not comparable to $z$, then there exists $x \in X$ comparable Monotonicityimplies that $\mathrm{T}^{\mathrm{n}} \mathrm{x}$ is comparable to $\mathrm{T}^{\mathrm{n}} \mathrm{y}=\mathrm{y}$ and $\mathrm{T}^{\mathrm{n}} \mathrm{z}=\mathrm{z}$ for $\mathrm{n}=0$, If there exists $\mathrm{n}_{0} \geq 1$ such that $T^{n_{0}} \mathrm{x}=\mathrm{y}$, then as $\mathrm{y}$ is a fixed point, the sequen $\left\{\mathrm{T}^{\mathrm{n}} \mathrm{x}: \mathrm{n} \geq \mathrm{n}_{0}\right\}$ is constant and consequently $\lim _{n \rightarrow \infty} T^{n} x=y$.

Hence, we conclude that $\lim _{n \rightarrow \infty} T^{n} x=y$.

Using a similar argument, we can prove that

$$
\lim _{n \rightarrow \infty} T^{n} x=z \text {. }
$$

Now, the uniqueness of the limit gives us $y=z$. Hence proved the theorem.

Remark 2.5 : It is easily proved that the space 0,1$]=\{\mathrm{x}:[0,1] \rightarrow \mathrm{R}$, continuous $\}$ with the partial order given by $\mathrm{x} \leq \mathrm{y} \Leftrightarrow \mathrm{x}(\mathrm{t}) \subset \mathrm{y}, \mathrm{t} \in\left[\begin{array}{ll}0 & 1\end{array}\right]$, and metric is given by $d(x, y)=\{\mid x(-v(t) \mid: \in[0,1]\}$ satisfies condition : if $\left\{\mathrm{x}_{\mathrm{n}}\right\} \mathrm{i}$, a rond easings equence in $\mathrm{X}$ such that $\mathrm{x}_{\mathrm{n}} \rightarrow \mathrm{x}$, then $\mathrm{x}=\sup \left\{\mathrm{x}_{\mathrm{n}}\right.$ Moreover, as for $x, y=C[1]$, the function $\max (x, y)(t)=\max \{x(t), y(t)\}$ is continuous, $(\mathrm{C}[0,1,5)$ satisfie, also condition : For $\mathrm{x}, \mathrm{y} \in \mathrm{X}$ there exists $\mathrm{z} \in \mathrm{X}$ which is comparable to

\section{Som Ren $\mathbf{k s}$}

Reman 1 theorems of Section $2, \beta=0$, we obtain the following fixed point theorem in partially o, red complete metric space .

Theorem 3.2: Let $(\mathrm{X}, \leq$ ) be a partially ordered set and suppose that there exists a metric $\mathrm{d}$ in $\mathrm{X}$ such that $(X, d)$ is a complete metric space. Let $\mathrm{T}: \mathrm{X} \rightarrow \mathrm{X}$ be a nondecreasing mapping such that there exists $a \in[0,1)$ satisfying

$$
d(T x, T y) \leq \alpha\left(\frac{d(x, T x)+d(y, T y)}{d(x, y)+d(x, T x)}\right) d(x, T x), \text { for } x, y \in X, x \geq y, x \neq y
$$

Suppose also that either $\mathrm{T}$ is continuous or $\mathrm{X}$ satisfies condition : If $\left\{\mathrm{x}_{\mathrm{n}}\right\}$ is a nondecreasing 
sequence in $X$ such that $x_{n} \rightarrow x$, then $x=\sup \left\{x_{n}\right\}$.

If there exists $\mathrm{x} 0 \in \mathrm{X}$ with $\mathrm{x} 0 \leq \mathrm{Tx} 0$, then $\mathrm{T}$ has a fixed point.

Besides, if ( $\mathrm{X}, \leq$ ) satisfies the condition : For $\mathrm{x}, \mathrm{y} \in \mathrm{X}$ there exists $\mathrm{z} \in \mathrm{X}$ which is comparable to $\mathrm{x}$ and $y$, then one obtains uniqueness of the fixed point.

Example 3.3 : Let $X=\{(0,1),(1,0),(1,1)\}$ and consider in $X$ the partial order given by $R$ $=\{(\mathrm{x}, \mathrm{x}): \mathrm{x} \in \mathrm{X}\}$. Notice that elements in $\mathrm{X}$ are only comparable to themselves.

Besides $\left(X, d_{2}\right)$ is a complete metric space considering $d_{2}$ the Euclidean distance.

Let $\mathrm{T}: \mathrm{X} \rightarrow \mathrm{X}$ be defined by $\mathrm{T}(0,1)=(1,0), \mathrm{T}(1,0)=(0,1), \mathrm{T}(1,1)=(1$

$\mathrm{T}$ is trivially continuous and nondecreasing and

$d(T x, T y) \leq \alpha\left(\frac{d(x, T x)+d(y, T y)}{d(x, y)+d(x, T x)}\right) d(x, T x)+\beta d(x, y)$

is satisfied, Sin enents $\mathrm{X}$ are only

comparable to themselves. Moreover $(1,1) \leq \mathrm{T}(1,1)=(1,1)$ a d by theo $2.2 T$ has a fixed point . ( Obviously this fixed point is $(1,1)$ ).

On the other hand, for $x=(0,1) y=(1,0) \in X$, we have $d(T y)=\sqrt{ }(x, T x)=\sqrt{2}$

$\mathrm{d}(\mathrm{y}, \mathrm{Ty})=\sqrt{2}, \mathrm{~d}(\mathrm{x}, \mathrm{y})=\sqrt{2}$ and the contractive condi on is not satisfiec oecause

$$
\begin{aligned}
d(T x, T y)=\sqrt{2} \leq \alpha & \left(\frac{d(x, T x)+d(y, T y)}{d(x, y)+d(x, T x)}\right) d(x, T x)+\gamma(x, y) \\
& \left.=\alpha\left(\frac{\sqrt{2}+\sqrt{2}}{\sqrt{2}+\sqrt{2}}\right) \sqrt{2}+\beta \sqrt{-}=\sqrt{2}\right) \sqrt{2}
\end{aligned}
$$

and thus $\alpha+\beta \geq 1$.

Moreover, notice that in this $\mathrm{m}_{\mathrm{P}}$ uniqueness of fixed point and $(\mathrm{X}, \leq)$ does not satisfy Condition : for $\mathrm{x}, \mathrm{y}$, , there $\mathrm{e}, \mathrm{X} \in \mathrm{X}$ which is comparable to $\mathrm{x}$ and $\mathrm{y}$. This condition is not necessary condition or th niquenes; of the fixed point.

\section{References}

[1] D. S. Jag "Some ique fixed point theorems," Indian Journal of Pure and Applied M vatics, 1. 8. 10. 2, pp. 223-230, 1977.

2] P. garwal, 1. A. El-Gebeily, and D. O'Regan, "Generalized contractions in partially spaces,” Applicable Analysis, vol. 87, no. 1, pp. 109-116, 2008.

[3] T. O Bhaskar and V. Lakshmikantham, "Fixed point theorems in partially ordered metric spaces and applications," Nonlinear Analysis: Theory, Methods \&Applications, vol. 65, no. 7, pp. 1379-1393,2006.

[4] J. Harjani and K. Sadarangani, "Fixed point theorems for weakly contractive mappings in partially ordered sets," Nonlinear Analysis: Theory, Methods \& Applications, vol. 71, no. 78, pp. 3403-3410, 2009.

[5] J. Harjani and K. Sadarangani, "Generalized contractions in partially ordered metric spaces and applications to ordinary differential equations," Nonlinear Analysis: Theory, Methods \& Applications, vol. 72, no. 3-4, pp. 1188-1197, 2010.

[6] V. Lakshmikantham and L. Ciric, "Coupled fixed point theorems for nonlinear contractions 
in partially ordered metric spaces," Nonlinear Analysis: Theory, Methods \& Applications, vol. 70, no. 12, pp. 4341-4349, 2009.

[7] J. J. Nieto and R. Rodríguez-López, "Existence of extremal solutions for quadratic fuzzy equations," Fixed Point Theory and Applications, vol. 2005, no. 3, pp. 321-342, 2005.

[8] J. J. Nieto and R. Rodríguez-López, "Contractive mapping theorems in partially ordered sets and applications to ordinary differential equations," Order, vol. 22, no. 3, pp. 223-239, 2005.

[9] J. J. Nieto and R. Rodríguez-López, "Applications of contractive-like mapping principles to fuzzy equations,” Revista Matemática Complutense, vol. 19, no. 2, pp. 361-383, 2006.

[10] J. J. Nieto, R. L. Pouso, and R. Rodríguez-López, "Fixed point theorems in ouercen tract spaces," Proceedings of the American Mathematical Society, vol. 135, no. pp. 2505 17, 2007.

[11] J. J. Nieto and R. Rodríguez-López, "Existence and uniqueness fix a poî in partially ordered sets and applications to ordinary differential equati ns, Av Mathe atica Sinica, vol. 23, no. 12, pp.2205-2212, 2007.

[12] D. O'Regan and A. Petruşel, "Fixed point theorems fo. genen contractions in ordered metric spaces," Journal of Mathematical Analys and Applica $\%$, vol. 341, no. 2, pp.
1241-1252, 2008.

[13] A. Petruşel and I. A. Rus, "Fixed point theore in ordered L-spaces," Proceedings of the American Mathematical Society, vol. 134, no. 2, 411-41 o, 2006.8

[14] A. C. M. Ran and M. C. B. Reurings, point theorem in partially ordered sets and some applications to matrix equations," ocean the American Mathematical Society,
vol. 132, no. 5, pp.1435-1443,2004.

[15] Y. Wu, "New fixed point t' eoren and apt Cations of mixed monotone operator," Journal of Mathematical Analysis ap ap. vol. 341, no. 2, pp. 883-893, 2008.

[16] A. Cabada and J. J vieto, "F. points and approximate solutions for nonlinear operator equations," Jourr al Computaty al and Applied Mathematics, vol. 113, no. 1-2, pp. 17$25,2000$. 